\title{
SIMULATION AND ANALYSIS OF BALL-END MILLING OF PANEL MOULDS BASED ON DEFORM 3D
}

\author{
Yang, L. \& Zheng, M. L." \\ The Key Lab of National and Local United Engineering for "High- Efficiency Cutting \& Tools", \\ Harbin University of Science and Technology, Harbin 150080, P. R. China \\ E-Mail: minli@ hrbust.edu.cn ( ${ }^{\#}$ Corresponding author)
}

\begin{abstract}
Automobile panel moulds are assembled pieces with various surface features, making it difficult to predict the machining properties in ball-end milling process. In this paper, Deform 3D finite element analysis software is used to simulate the ball-end milling of multi-hardness assembled moulds, and to analyse the distribution patterns of milling forces, stress fields and temperature fields in the transition regions of the multi-hardness assembled moulds. Subsequently, milling of sine surface moulds is simulated, and the effects of milling parameters on the thermal performance of sine surfaces are analysed. Finally, the multi-hardness assembling and milling experiment and the sine surface mould milling experiments are conducted to verify the effectiveness of the Deform 3D finite element simulation method.

(Received, processed and accepted by the Chinese Representative Office.)
\end{abstract}

Key Words: Ball-End Milling, Panel Mould, Simulation, Deform 3D

\section{INTRODUCTION}

Automobile panel moulds are large in size with complex surface shapes and require a high level of dimension and surface precision. The mould materials are mostly die steel such as $\mathrm{Cr} 12 \mathrm{MoV}$ and $7 \mathrm{CrSiMnMoV}$, which are typically high-strength and high-hardness materials after quenching hardness of HRC50-65 [1]. In order to form some complex surfaces, the hardened steel panel moulds often need to be assembled by multiple moulds with different surface curvatures and different degrees of hardness. When a ball-end milling cutter is passing the assembled transition region with different degrees of hardness, the milling layer parameters and the milling force coefficient are constantly changing, resulting in extremely unstable loads during machining, and making it difficult to predict the milling force and the distribution of the stress field and the temperature field in the transition region of the workpiece. In addition, in milling of a curved surface, the tool contact relationship is constantly changing along the tool path, and the thermal performance of milling changes with changes in the shape characteristics. In high-speed machining, the finite element method not only can effectively simulate the contact relationship of the tool, but also can obtain the distribution pattern of the physical field of workpieces and tools in the cutting process, so as to provide a reference for selecting process parameters and tool design [2].

During the milling and assembling of hardened steel moulds (oblique cutting under nonfree state), due to the sudden changes in local hardness, the cutting edge will contact materials with different degrees of hardness at the same time. In this instance in the feed process, the tool will transition from cutting the single-hardness material to the multi-hardness material and finally to the single-hardness material. This process is referred to as the milling transition region. When the milling cutter is in the milling transition region, in the machining area of the material with relatively high hardness, the cutting chips cannot be easily deformed. With the same cutting edge, the deformed and un-deformed chips will extrude each other, causing the milling force and temperature to fluctuate, and thus affecting the consistency of local surface integrity and resulting in differences in the performances of the workpieces. 
Seshadri et al. acquires characteristic parameters such as milling force and milling temperature by using DEFORM-2D finite element software with milling parameters as the variable factors, and compares them with the milling force and milling temperature measured in the milling experiment. The results show that the established J-C model has high accuracy [3]. Leopold and Wohlgemuth used the finite element model to analyse the impacts of the friction factor on the cutting shape. The results show that with an increase in the friction coefficient, the friction becomes more severe and the cutting heat is increase [4]. Zanger and Schulze used the finite element method to analyse the stress field, temperature field and tool wear of the uncoated hard alloy cutting tool in the high-speed Ti-6Al-4V cutting process, and compared the results with the tool wear in the experiment so as to analyse the wear mechanism of the hard alloy cutting tool in the Ti-6Al-4V cutting process [5]. Zhang et al. used finite element software to simulate the 3D multi-hardness assembling and milling process. The results show that the milling force of the assembled transition region changes abruptly and the milling force increases with the hardness of hardened steel [6]. Chen et al. considered the range of milling temperature variation caused by the milling speed and the feed rate. The temperature of the tool contact surface and the distribution pattern of the temperature field are investigated in high-speed milling of aluminium alloy thin-walled parts [7]. Bin et al., by establishing the finite element model and using the finite element calculation software, simulated the milling process of 45 steel with a ceramic cutting tool. Through comparison, it was found that the simulation results were in conformity with the experimental data [8]. Based on the theoretical analysis and the finite element computation method, Cheng et al. analysed various technologies such as chip separation standards, friction criterion and thermal stress coupling analysis, and employed finite element software to analyse the impacts of various factors on stress and strain. Based on the analysis results, the strength of tools was analysed [9].

Wang et al. analysed the impacts of milling parameters on acceleration response under both the single-hardness and multi-hardness assembling conditions. The results show that in the multi-hardness transition region, the acceleration signal peak shows step changes [10]. Du and Chen used the AdvantEdge software to analyse the turning force, cutting temperature, stress and cutting chips of $\mathrm{H} 13$ hardened steel. The research conclusions can be used for the optimization of process parameters in the hard-cutting process and the selection and design of tools and coating materials [11]. Li et al. simulated the effects of the cutting speed, cutting depth and workpiece hardness on the milling force using the ABAQUS software, which revealed the characteristics of the milling force on the hardened steel with different degrees of hardness [12]. Wen et al. used the AdvantageEdge software to simulate the ball-end milling process of hardened steel with different degrees of hardness, obtained the milling force and milling temperature distribution of hardened steel with different degrees of hardness and concluded that the milling temperature field in the high-hardness material in the multihardness assembling is not evenly distributed [13].

The above studies are of great theoretical and practical value to the analysis of the milling characteristics of hardened steel moulds and curved-surface hardened steel moulds under assembling conditions. However, there are few studies on the milling characteristics of the transition region of the hardened steel mould under high-speed milling and multi-hardness assembling conditions. As a result, the effects of milling parameters on the thermal field of multi-hardness assembled quenched die steel and the distribution pattern of the thermal field in the transition region remain unclear. In the ball-end milling of curved surface, the tool contact relationship is complicated, making it very difficult to control the stability of the cutting process. Studying these problems by simply relying on experimental means is both time-consuming and costly, and it is very difficult to accurately obtain the cutting stress and cutting temperature field in the milling process $[14,15]$. Therefore, in this paper, focusing on 
the multi-hardness assembled transition regions and surface regions of the hardened steel moulds with complex surfaces, Deform 3D is used to simulate the milling process. In particular, with the sine surface as an example, Deform 3D is used to simulate the milling of a hardened steel mould with a curved surface to study the effects of milling parameters on the thermal performance, and the distribution pattern of thermal performance at different positions of the surface. This can provide the basis for the optimization of milling parameters of curved-surface and assembled moulds and help facilitate the analysis of surface integrity.

\section{FINITE ELEMENT ANALYSIS MODEL FOR THE BALL-END MILLING PROCESS OF ASSEMBLED AND CURVED-SURFACE HARDENED STEEL MOULDS}

Establishing a proper finite element analysis model for metal milling is the key to the success of simulation and also the basis and prerequisite for accurate and reliable of dynamic physical simulation results in the machining process [16]. Based on the geometrical model of the tool, the constitutive parameters of the material, the chip separation criterion and the boundary conditions, and by applying the Lagrangian interpolation algorithm and the meshing principle, a finite element model for hardened steel with different degrees of hardness is established. Fig. 1 shows, from left to right, the milling cutter, and hardened die steel (C12MoV) workpieces with a hardness of $42 \mathrm{HRC}, 52 \mathrm{HRC}$ and $62 \mathrm{HRC}$, respectively. The fit clearance between these workpieces is $0.2 \mathrm{~mm}$. The sinusoidal workpiece is a piece of hardened die steel $(\mathrm{C} 12 \mathrm{MoV})$ with a continuous face and hardness of $60 \mathrm{HRC}$. The finite element model is shown in Fig. 2. In order to lessen the time needed to resolve the finite element model so as to shorten the simulation cycle, based on the meshing method and the resolving time regularity, some workpieces in the simulation are simplified as appropriate.
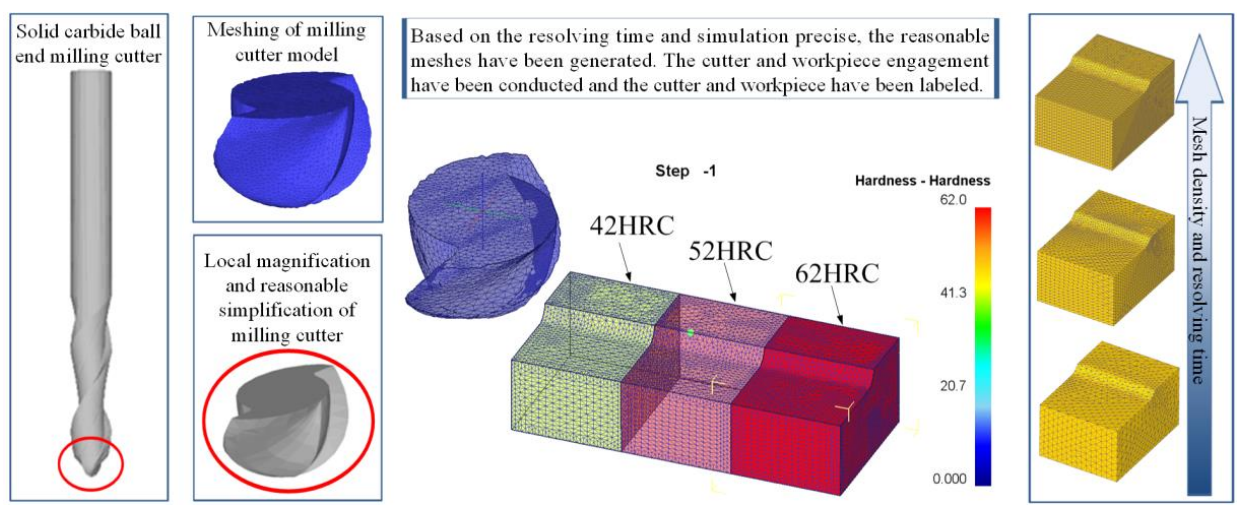

Figure 1: Finite element model for hardened steel with different degrees of hardness.
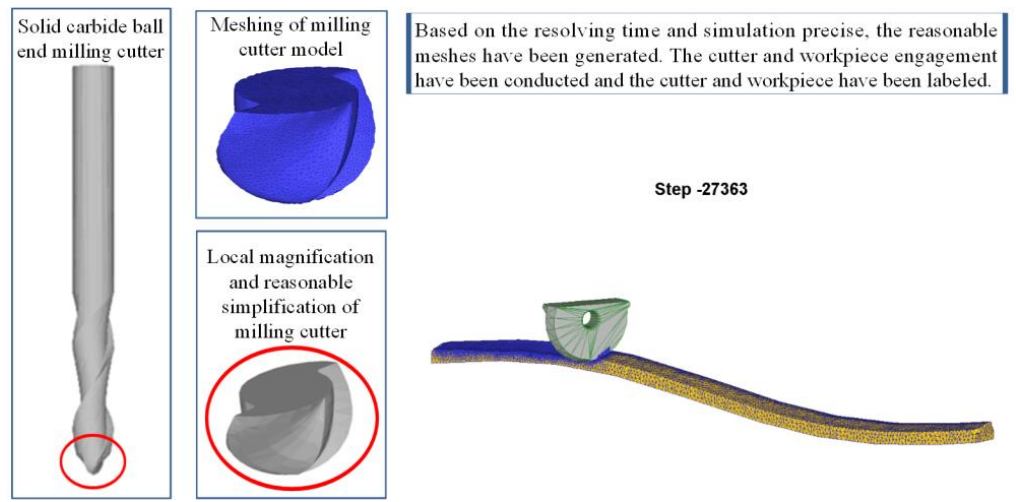

Figure 2: Finite element model for milling of curved surface. 


\section{FINITE ELEMENT ANALYSIS FOR THE BALL-END MILLING PROCESS OF ASSEMBLED HARDENED STEEL MOULDS}

\subsection{Analysis of milling force and temperature mutations in the assembled transition region}

There are four stages in the main milling force: cut-in, cut-out and two stages through the assembled transition region. The numerical milling forces are shown in Fig. 3, which shows that the milling force in the assembled region of the workpiece will increase step-wise. When the ball-end milling cutter cut into the workpiece ( $42 \mathrm{HRC}$ ), the amplitude of the milling force fluctuates little and reaches a relatively stable state. When the ball-end milling cutter enters the first assembled transition region, which is between the first workpiece (42 HRC) and the second workpiece (52 HRC), the peak milling force gradually enters a stable state after a certain period of step changes. But the stabilized peak milling force on the workpiece (52 HRC) is still greater than that on the workpiece (42 HRC). The reason for this is that when the tool enters the assembled transition region, due to the high material hardness of the workpiece (52 HRC), the resistance of the workpiece increases. As a result, under the same cutting edge, some of the cutting chips are largely deformed (42 HRC) and some are less deformed (52 HRC). The interaction between the two deformed chips causes the "squeezing effect" and leads to the mutation of the milling force. The above factors together cause the mutation of the milling force in the assembled transition region. The same phenomenon occurs when the tool cut into the transition region between the second block (52 HRC) and the third (62 HRC) transition region.
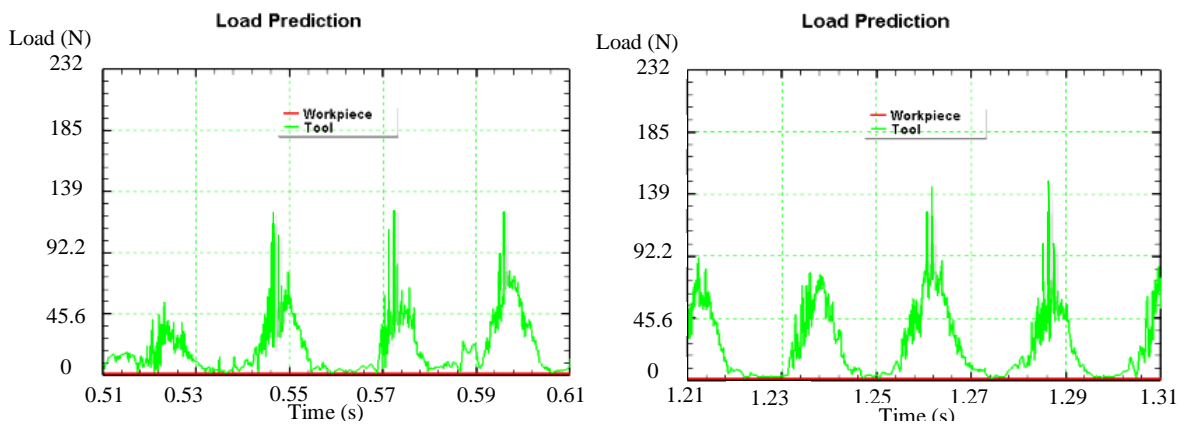

Figure 3: Simulated milling force in the first (left) and the second (right) transition region.

The milling temperature plays an important role in the surface integrity. It can be seen from Fig. 4 that the milling temperature produced by the high-hardness workpiece material is obviously higher than that of the low-hardness workpiece. The highest temperature appears on the material with a hardness of 62 HRC. During the simulation, the milling temperature fluctuates in a similar manner as in the milling force.
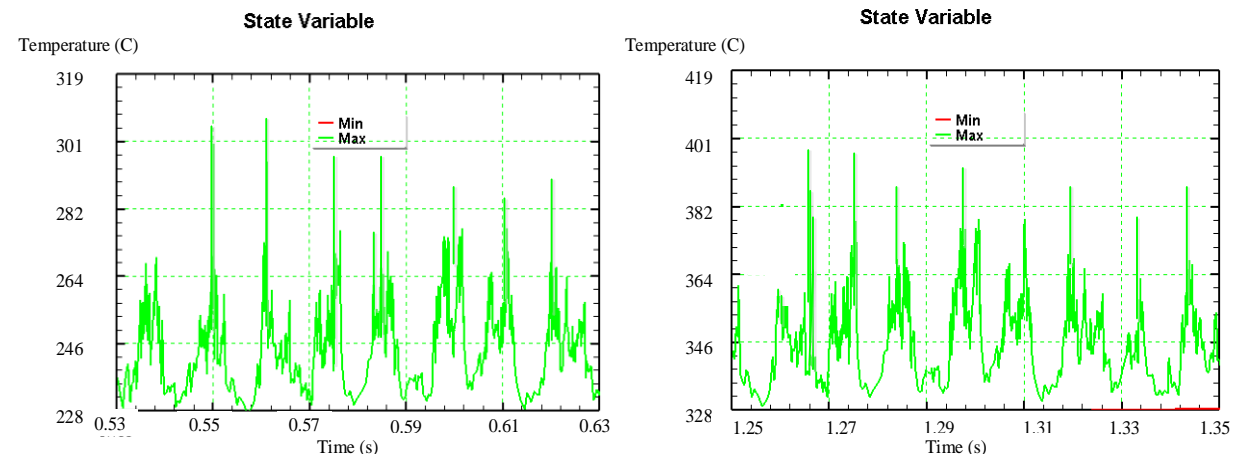

Figure 4: Simulated milling temperature in the first (left) and the second (right) transition region. 


\subsection{Distribution patterns of the stress field and the temperature field in the assembled transition region}

By extracting the simulation results of the assembled transition region during the milling process of hardened steel moulds, the distribution patterns of the stress field and the temperature field in the assembled transition region are obtained, respectively, as shown in Fig. 5.
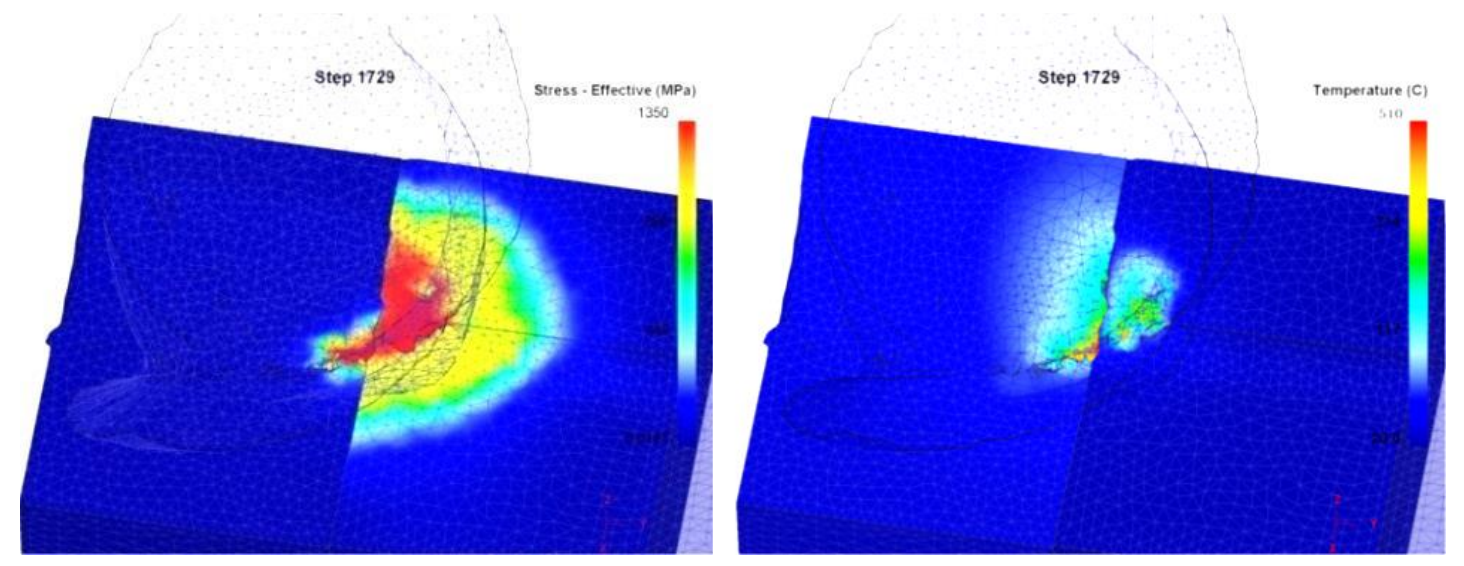

Figure 5: Distribution of stress (left) and temperature (right) field.

Fig. 5 reveals that there are significant differences in the distribution patterns of the temperature field and the stress field during the milling process of the metal in the transition region (in the same analytical step). This singular phenomenon is ultimately caused by the constitutive changes in the material. In this paper, the J-C constitutive model is adopted. The difference in the hardness affects the initial yield stress $A$ and the strain hardening coefficient $B$ of the material, and the stress-strain curve rises with an increase in hardness, which indicates that the elastic modulus $E$ is increased [17].

$$
\bar{\sigma}=\left[A+B(\bar{\varepsilon})^{n}\right]\left[1+C \ln \left(\frac{\dot{\bar{\varepsilon}}}{\dot{\overline{\varepsilon_{0}}}}\right)\right]\left[1-\left(\frac{T-T_{0}}{T_{m}-T_{0}}\right)^{m}\right]
$$

where, $\dot{\bar{\varepsilon}}$ is the equivalent plastic strain rate; $T_{0}$ is the room temperature; $T_{m}$ is the hot melting parameter; $n, m$ and $c$ stand for the strain hardening index, heat softening index and strain-rate sensitivity, respectively.

It can be seen from Fig. 5 (left) that for a high-hardness workpiece, the milling force acts on a large range of the stress field on its surface, while for a low-hardness workpiece, the tool can only act on a small range of the stress field. This is because the hardness of the material represents the resistance of the metal material against any other hard object into its surface, that is, the resistance of the metal material against local plastic deformation has certain relationships with the tensile strength limit and yield strength limit of the material [18]. A similar phenomenon occurs when the tool is passing another transition region, further validating the correctness of the analysis.

In contrast to the distribution of the stress field, Fig. 5 (right) reveals that, during the same milling process, in the temperature field of the workpiece with a lower hardness (42 HRC), the milling temperature diffusion is more obvious, while for the workpiece with a higher hardness (52 HRC), the temperature field distribution is more concentrated. In the assembled transition region between the workpieces ( $52 \mathrm{HRC}$ and $62 \mathrm{HRC}$ ), a similar phenomenon occurs. For the same material $(\mathrm{Cr} 12 \mathrm{MoV})$, the lower the hardness is, the more uniform the temperature field distribution will be. From a microscopic point of view, the hardness of a material is not determined by atoms and ions, but rather by the hardness of the chemical bond, and has a linear relation with the bond hardness [19]. 


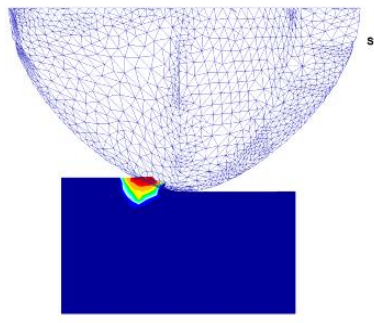

a)Stress field with hardness of 42HRC

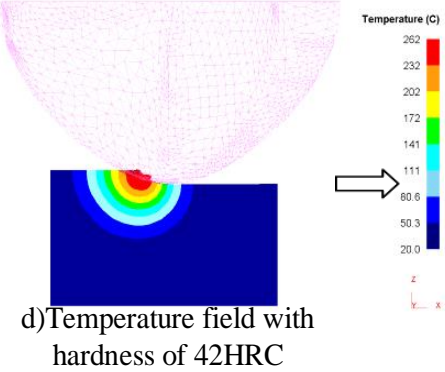

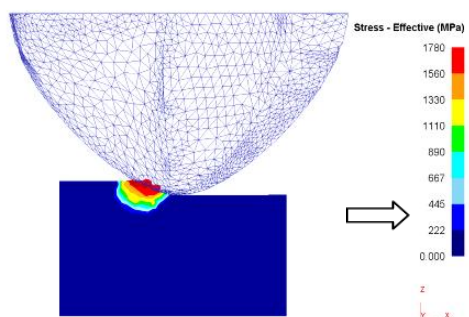

b)Stress field with hardness of 52HRC

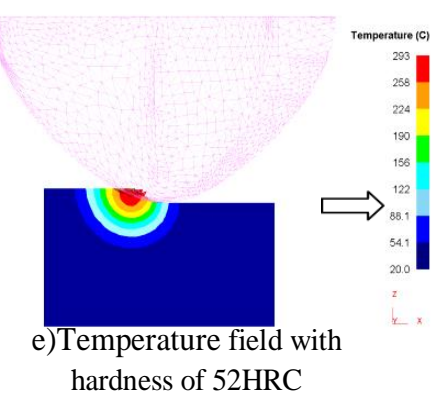

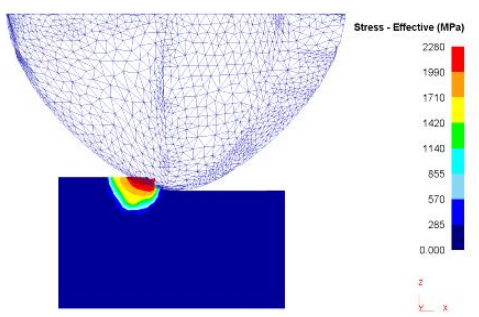

c)Stress field with hardness of $62 \mathrm{HRC}$

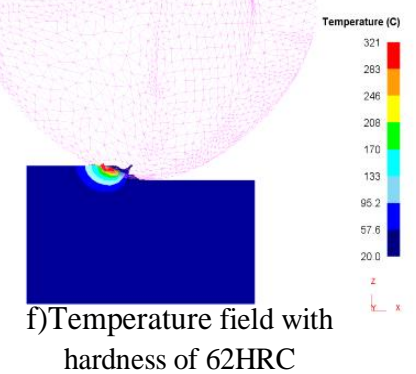

Figure 6: Numerical simulation of stress and temperature field with single hardness.

In order to further prove the singular distribution of the stress field and the temperature field in the assembled transition region, milling of workpieces $(\mathrm{Cr} 12 \mathrm{MoV})$ with a hardness of $42 \mathrm{HRC}, 52 \mathrm{HRC}$ and $62 \mathrm{HRC}$ is simulated, respectively, and the distribution of the stress field and the temperature field in the workpieces in the same analytical step is extracted. It can be seen from Fig. 6 that the influence range of the stress field gradually increases with an increase in the hardness of the workpiece, and the influence range of the temperature field decreases gradually. The influence range of the stress field is significantly larger than that of the temperature field when the workpiece hardness is $62 \mathrm{HRC}$. The milling temperature is concentrated, the temperature field bandwidth is narrower and the gradient is larger. Compared with the distribution of the stress field and the temperature field of the assembled transition region, the field distributions of the single-hardness workpiece do not vary much. The reason for this is that there is a gap in the assembled transition region, so the field distribution is concentrated and the milling force and milling temperature do not fluctuate greatly in the stable region of the single-hardness workpiece.

\section{FINITE ELEMENT ANALYSIS OF THE MILLING PROCESS OF THE HARDENED STEEL MOULDS WITH SINE SURFACES}

\subsection{Import of the tool path for finite element analysis}

In the surface mould milling simulation, the tool path is curved. The simulation software's ability to accurately identify the tool path is the key to the simulation accuracy. The DEFORM-3D software provides users with simple tool paths, so horizontal and slash paths and arc paths with constant curvatures are used as approximate substitutes for paths of complex movement to simulate the milling process. However, these method ignores the curved tool path can cause variations in the milling parameters and further cause differences in the thermal distribution, which would make the analysis result inaccurate. Therefore, the reserved "interface" in the DEFORM-3D is applied, with the sine surface model considering the surface characteristics and the tool path. By using the cutter location point as the reference point, the discrete points distributed in the sine path are calculated according to the tool path generated. The sine surface correction function is $x=v ; y=u ; z=2 \cdot \sin (\pi \cdot v / 40)$. Matlab is applied to calculate the discrete points, extract the discrete points and post-process them into a dat file, and then the tool path is imported into the DEFORM-3D software. The process in 
which DEFORM 3D reads the tool path is as follows: (1) reading of the initial conditions; (2) time cycle; (3) iterative solution; (4) calculation of stress, strain and temperature field, etc.; (5) contact search; (6) distorted grid re-division; (7) tool position update; (8) end of the cycle.

\subsection{Analysis of the stress and the temperature in milling of sine surface}

Seven feature reference points are selected on the sine surface as shown in Fig. 7. The feed direction is "from Point 1 to Point 8" as well as "from convex to concave". Going up along the convex surface means the axial feed direction is $+\mathrm{Z}$, and going down along the convex surface means the axial feed direction is $-\mathrm{Z}$. It is the same with the concave surface. By using the minimum principal curvature and maximum principal curvature formulas, Point-1, Point2, Point-3 and Point-4 are on a convex parabolic surface $K=0, H<0$ (T), and Point-5, Point-6, Point-7 and Point- 8 are on a concave parabolic surface $K=0, H>0$ (A). Table I shows the properties of surfaces where each feature point is located.

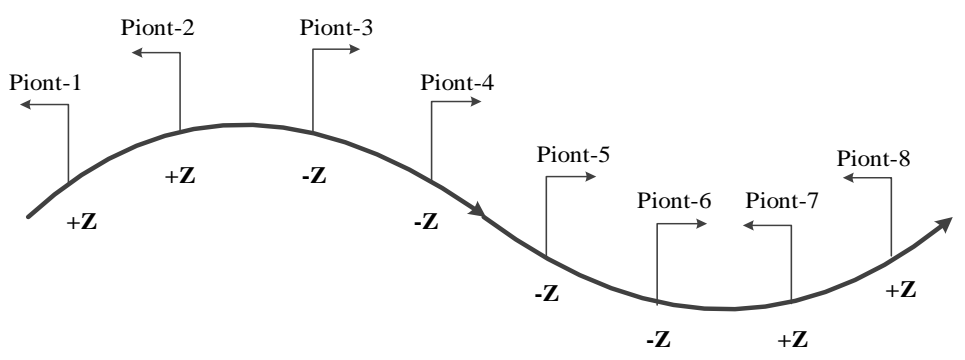

Figure 7: Feature reference point distribution.

Table I: Surface properties of each feature point.

\begin{tabular}{|c|c|c|c|c|c|c|c|}
\hline $\begin{array}{c}\text { Feature } \\
\text { point }\end{array}$ & Curvature & $\begin{array}{c}\text { Axial feed } \\
\text { direction }\end{array}$ & $\begin{array}{c}\text { Concavity } \\
\text { /convexity }\end{array}$ & $\begin{array}{c}\text { Feature } \\
\text { point }\end{array}$ & Curvature & $\begin{array}{c}\text { Axial } \\
\text { feed di- } \\
\text { rection }\end{array}$ & $\begin{array}{c}\text { Concavity } \\
\text { / convexity }\end{array}$ \\
\hline Point-1 & $K_{1}$ & $+\mathrm{Z}$ & $\mathrm{T}$ & Point-5 & $K_{1}$ & $-\mathrm{Z}$ & $\mathrm{A}$ \\
\hline Point-2 & $K_{2}$ & $+\mathrm{Z}$ & $\mathrm{T}$ & Point-6 & $K_{2}$ & $-\mathrm{Z}$ & $\mathrm{A}$ \\
\hline Point-3 & $K_{2}$ & $-\mathrm{Z}$ & $\mathrm{T}$ & Point-7 & $K_{2}$ & $+\mathrm{Z}$ & $\mathrm{A}$ \\
\hline Point-4 & $K_{1}$ & $-\mathrm{Z}$ & $\mathrm{T}$ & Point- 8 & $K_{1}$ & $+\mathrm{Z}$ & $\mathrm{A}$ \\
\hline
\end{tabular}

The simulation results of stress field and temperature field are shown in Figs. 8-11. Fig. 8 (left) shows the variation of the stress field with the spindle speed. As the spindle speed increases, the corresponding milling stress of each feature point increases slowly. When the spindle speed is $4000 \mathrm{r} / \mathrm{min}$, the stress of each feature point is the closest. When the spindle speed $n$ is $1000 \mathrm{r} / \mathrm{min}$, the stress of each feature point is anisotropic and the consistency of milling stress is the worst. As shown in Fig. 8 (right), with an increase in the feed per tooth, the milling stress shows a fluctuant change and is generally on an upward trend. When the feed per tooth is $0.1 \mathrm{~mm} / \mathrm{z}$, the consistency of milling stress is the best, and when the feed per tooth is $0.05 \mathrm{~mm} / \mathrm{z}$, the milling stress is the most anisotropic, and its consistency is the worst.

As shown in Fig. 9 (left), with an increase in the path interval $a_{e}$, the milling stress does not vary much. When the path interval $a_{e}$ is $0.2 \mathrm{~mm}$, the corresponding stress parameter of each feature point is the closest, and the consistency of milling stress is the best. When the path interval $a_{e}$ is $0.1 \mathrm{~mm}$ and $0.6 \mathrm{~mm}$, the consistency of milling stress is the worst. As shown in Fig. 9 (right), the milling stress is most affected by the cutting depth $a_{p}$. When the cutting depth $a_{p}$ is $0.1 \mathrm{~mm}$, the corresponding milling stress parameter of each feature point is the closest, and the consistency of milling stress is the best. When the depth $a_{p}$ is $0.2 \mathrm{~mm}$, the milling stress is singular, and with an increase in the cutting depth $a_{p}$, the milling stress is more anisotropic and its consistency becomes increasingly worse. 

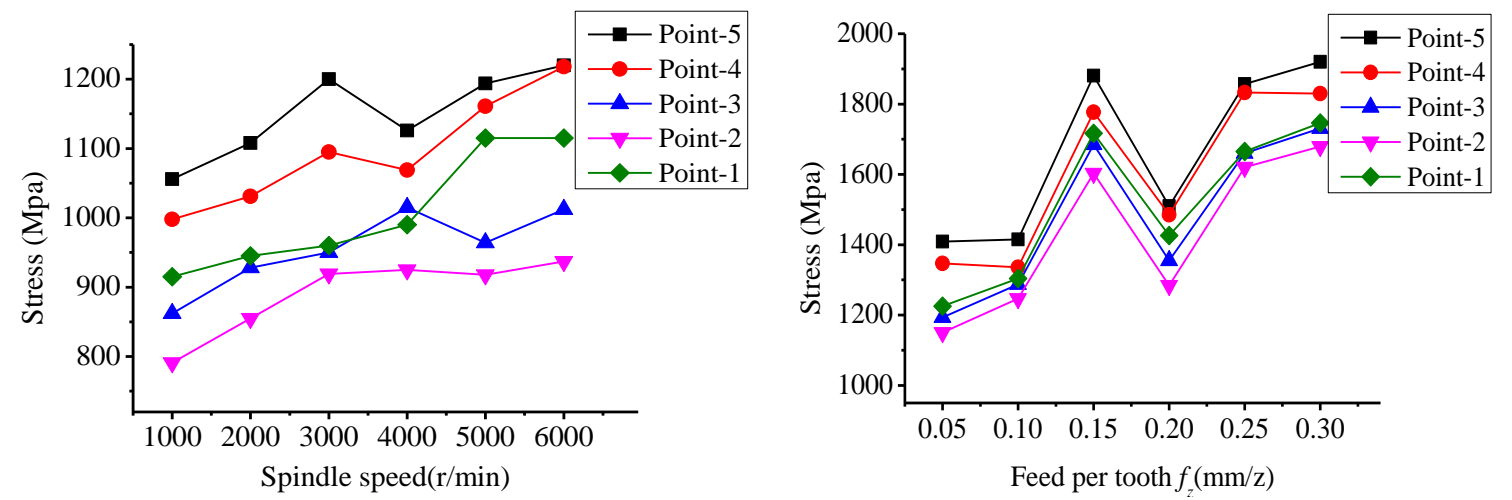

Figure 8: Stress field changing with various spindle speeds (left) and feeds per tooth (right).
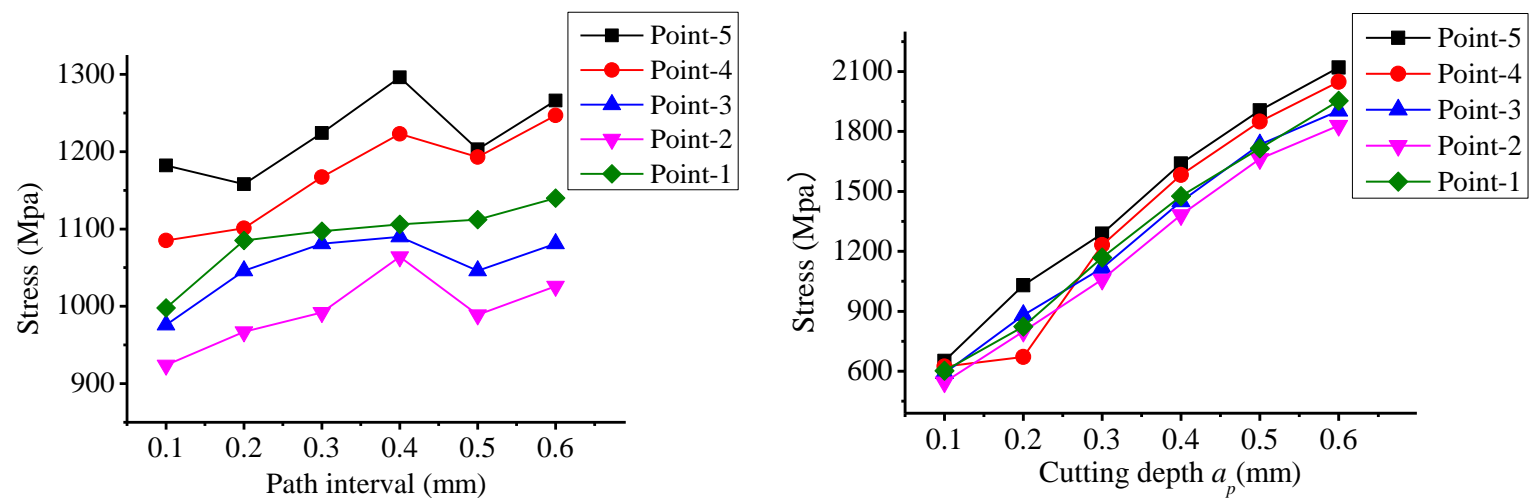

Figure 9: Stress field changing with various path intervals (left) and cutting depths (right).

Fig. 10 (left) shows the variation pattern of the temperature field with the milling parameters. With an increase in the spindle speed, the corresponding milling temperature of each feature point increases slowly. When the spindle speed is $4000 \mathrm{r} / \mathrm{min}$, the corresponding milling temperature parameter of each feature point is most similar. As shown in Fig. 10 (right), the milling temperature increases slowly with an increase in the feed per tooth $f_{z}$. When the feed per tooth is $0.1 \mathrm{~mm} / \mathrm{z}$, the milling temperature parameter is most consistent. As the path interval $a_{e}$ increases, the milling temperature parameter gradually increases.
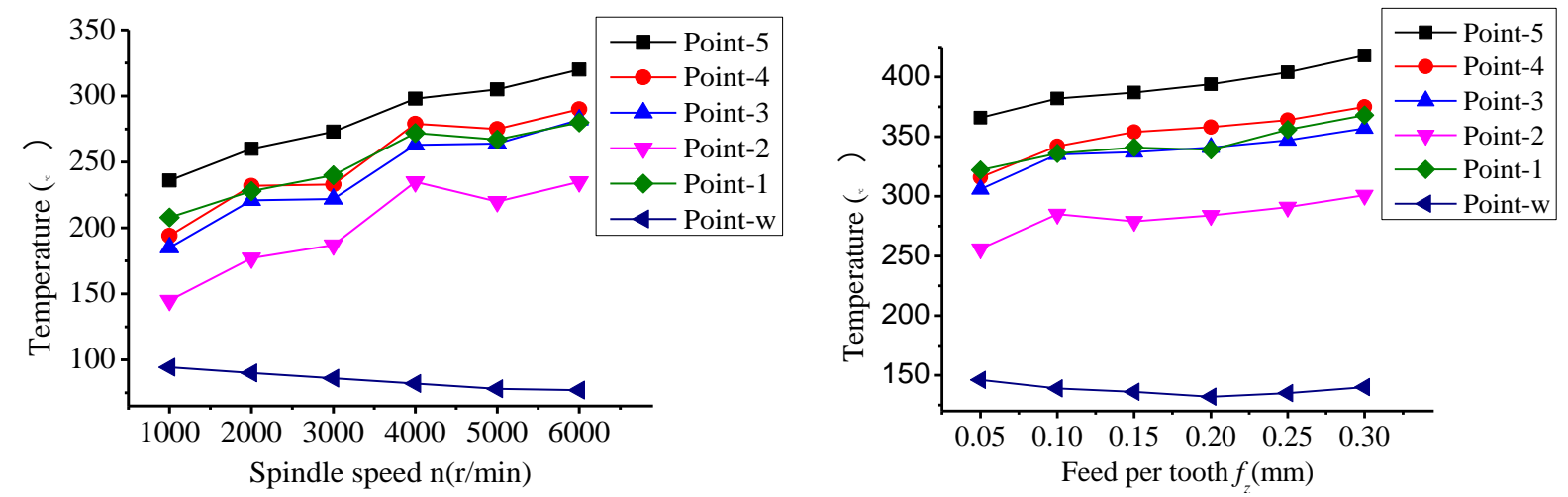

Figure 10: Temperature field changes with various spindle speeds (left) and feeds per teeth (right).

As shown in Fig. 11 (left), when the path interval $a_{e}$ is $0.2 \mathrm{~mm}$, the corresponding milling temperature parameter of each feature point is the closest, meaning the consistency of milling temperature is the best. As shown in Fig. 11 (right), the milling temperature is most affected by the cutting depth $a_{p}$. When the cutting depth $a_{p}$ is $0.1 \mathrm{~mm}$, the corresponding milling temperature parameter of each feature point is the closest and the consistency of milling 
temperature is the best. Based on the above analysis, the milling temperature shows similar changes with a variation of the milling stress.
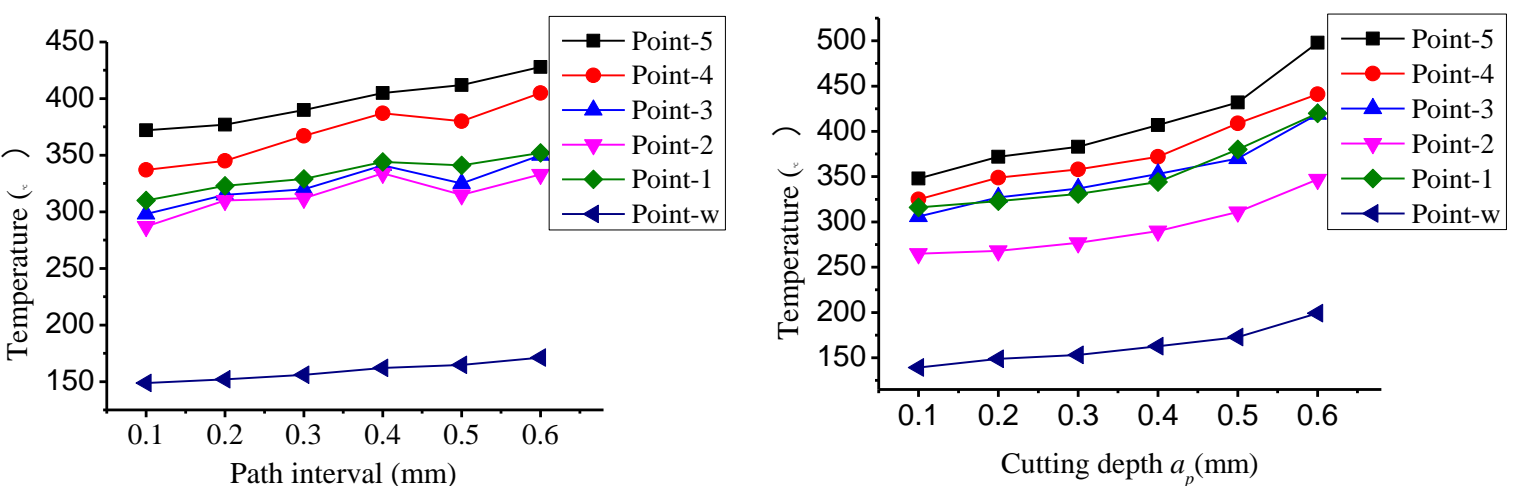

Figure 11: Temperature field changes with various path intervals (left) and cutting depths (right).

In the numerical analysis, the feature parameter of the milling temperature field of the workpiece transferred from Point-1 is denoted as Point-w. There is a large difference between the milling temperatures of the feature points Point- 1 and Point-w. This difference can be explained by the metal cutting principle, the chips absorb $50 \%-86 \%$ of the heat, the tool absorbs $10 \%-40 \%$, the workpiece absorbs $3 \%-9 \%$, and the surrounding media absorbs 1 $\%$ of the heat generated by the milling process. The feature parameter of the milling temperature field at Point-1 increases with an increase in the spindle speed, feed per tooth, path interval $a_{e}$ and cutting depth. The milling temperature field at Point-w shows similar changes to those at Point- 1 with variations in the path interval, cutting depth and feed per tooth, but it tends to decrease gradually with an increase in spindle speed. The main reason for this is that with the increase of the spindle speed, the chips absorb more heat, and due to the short contact time, the heat transferred to the workpiece is reduced. So when the spindle speed increases, the temperature in the first deformation region of the workpiece increases while the surface temperature in the third deformation region decreases.

\section{EXPERIMENT VERIFICATION}

The workpiece is hardened die steel $(\mathrm{Cr} 12 \mathrm{MoV})$. The quenched hardness of sine surface workpiece is $60 \mathrm{HRC}$. The dimension of the workpiece is $100 \times 48 \times 50 \mathrm{~mm}$. Three plane moulds are used in the multi-hardness assembling experiment with same size of $90 \times 70 \times 60 \mathrm{~mm}$. The quenched hardness is $42 \mathrm{HRC}, 52 \mathrm{HRC}$ and $62 \mathrm{HRC}$, respectively. The machine tool is VDL1000E. A Kistler 9257B dynamometer and a ThermoVision A40M infrared camera are used in the experiment to measure the milling force and milling temperature during the process of hardened steel milling with a ball-end milling cutter of $20 \mathrm{~mm}$ diameter as shown in Fig. 12.

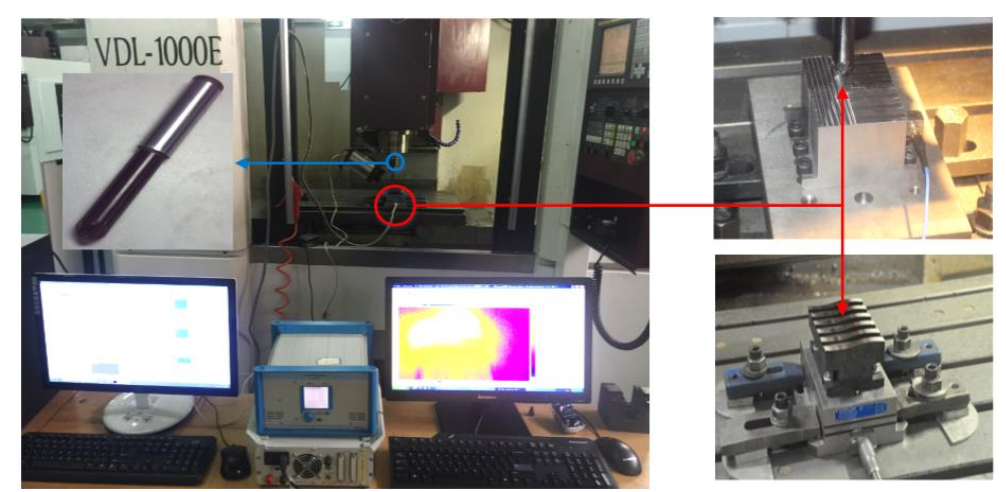

Figure 12: Milling experiments on multi-hardness assembled moulds and sine surface moulds. 
The parameters of the multi-hardness assembling experiment are consistent with the simulation parameters. The spindle speed is $5000 \mathrm{r} / \mathrm{min}$, the feed per tooth is $0.1 \mathrm{~mm}$ and the cutting depth is $0.2 \mathrm{~mm}$. The milling force is divided into three regions according to the hardness of the workpiece. The simulated results of the milling force and temperature are consistent with the measured results, as shown in Figs. 13 and 14, respectively. It is demonstrated that in the assembled region of the workpiece, the milling force will mutate. An increase in hardness makes the corresponding milling force and milling temperature increase.
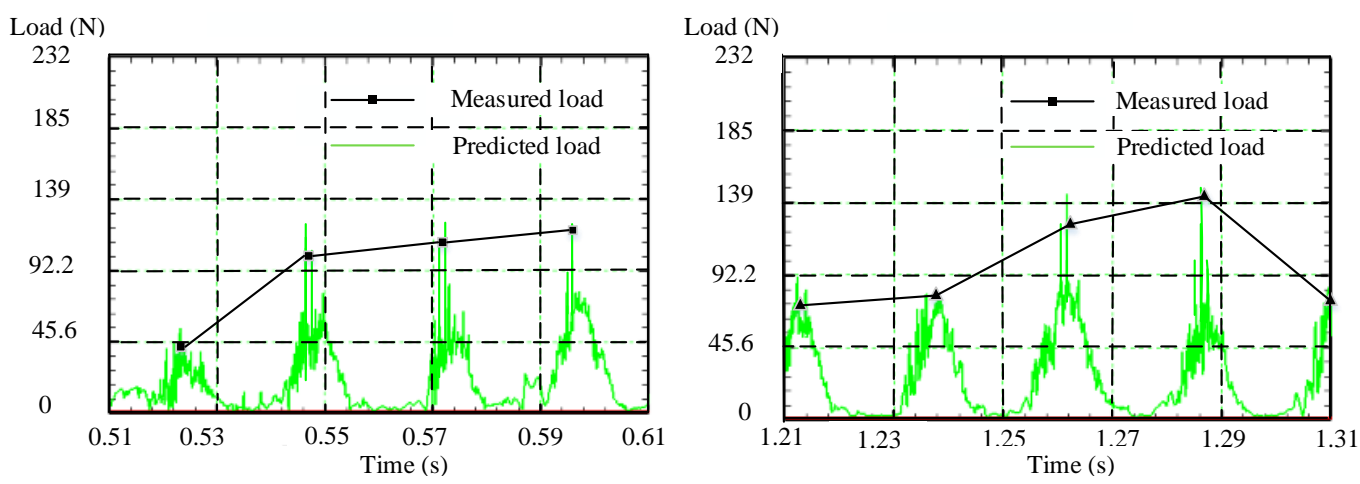

Figure 13: Comparison of simulated and measured load in the first (left) and second (right) transition region.
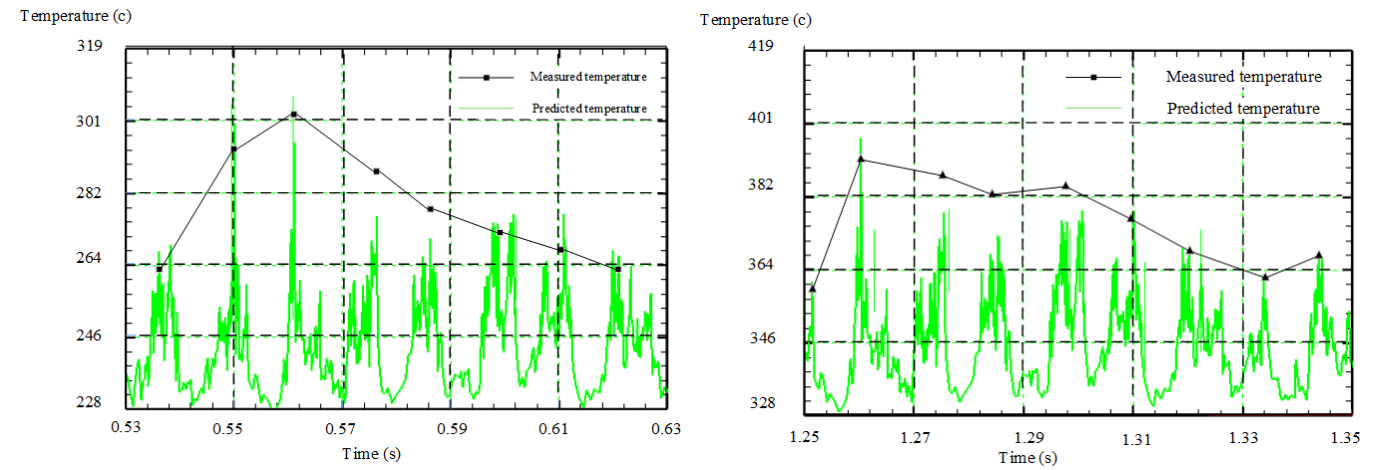

Figure 14: Comparison of simulated and measured temperature in the first (left) and second (right) transition region.

The cutting area of a mould with a continuous curved surface constantly changes with the tool path, and the surface features and milling parameters have great effects on the thermal performance of the ball-end milling. Therefore, a single-factor experiment is conducted to analyse and verify the thermal performance of the ball-end milling of sine surface moulds, as shown in Table II.

Table II: Parameters in the single factor experiment.

\begin{tabular}{|c|c|c|c|}
\hline $\begin{array}{c}\text { Spindle speed } \\
(\mathrm{r} / \mathrm{min})\end{array}$ & $\begin{array}{c}\text { Feed per tooth } \\
(\mathrm{mm} / \mathrm{z})\end{array}$ & $\begin{array}{c}\text { Path interval } \\
(\mathrm{mm})\end{array}$ & $\begin{array}{c}\text { Cutting depth } \\
(\mathrm{mm})\end{array}$ \\
\hline 1000 & 0.05 & 0.1 & 0.1 \\
2000 & 0.10 & 0.2 & 0.2 \\
3000 & 0.15 & 0.3 & 0.3 \\
4000 & 0.20 & 0.4 & 0.4 \\
5000 & 0.25 & 0.5 & 0.5 \\
6000 & 0.30 & 0.6 & 0.6 \\
\hline
\end{tabular}

It can be seen from Fig. 15 that the milling force and milling temperature of feature points Point-1, Point-2, Point-3, Point-4, Point-5, Point-6, Point-7 and Point-8 on the workpiece 
change in consistency in down milling of sine surface. The milling force and milling temperature at $\mathrm{P} 1$ and $\mathrm{P} 4$ are greater than that at $\mathrm{P} 2$ and $\mathrm{P} 3$, respectively. It is found that, in ball-end milling of convex surface the axial immersion angle gradually decreases with an increase in the workpiece curvature, while the lead angle increases. With milling parameters remaining unchanged, if the lead angle increases, the undeformed cutting thickness decreases. From the milling force model, the decrease in the undeformed cutting thickness results in the reduction of the joint milling force.

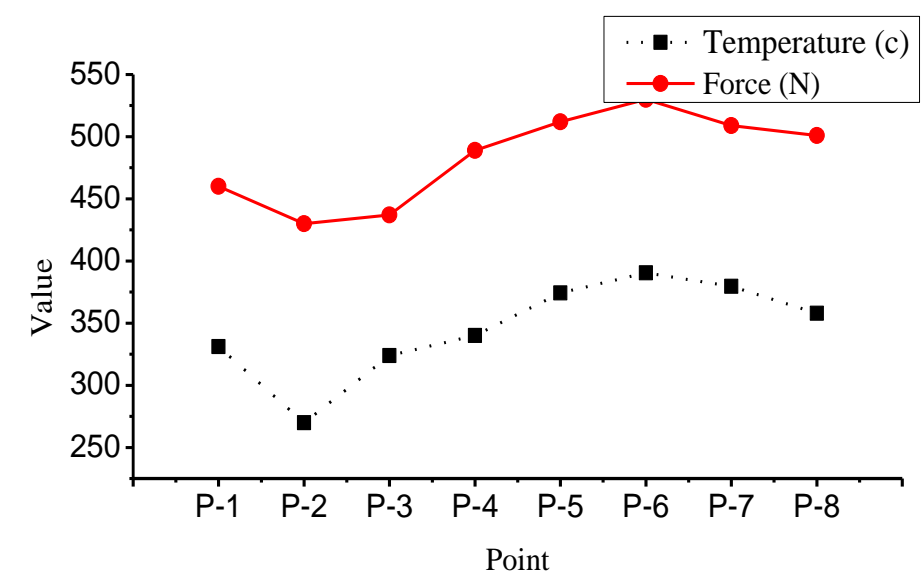

Figure 15: Milling force and temperature changes with the structural geometric features.

The curvature features $K$ of $\mathrm{P} 2$ and $\mathrm{P} 3$ as well as $\mathrm{P} 1$ and $\mathrm{P} 4$ are equal. The milling thermal condition generated by $\mathrm{P} 2$ is less than that generated by P3 while the milling thermal condition generated by $\mathrm{P} 1$ is less than that by $\mathrm{P} 4$ due to the difference of the axial feed direction. When the axial feed direction is $-\mathrm{Z}$, the axial incision angle makes the actual contact range greater, resulting in a slight increase in the milling force. In addition, the milling temperature rises as the milling force increases. It is indicated that during milling of the convex surface $\mathrm{T}$, with the workpiece curvature increasing, the milling force and milling temperature generated in the milling process decrease, and the milling temperature rises with an increase in milling force. The milling force and milling temperature generated when the axial feed direction is $-Z$ are greater than those generated when the axial feed direction is $+Z$.

P3 and P6 as well as P4 and P5 have the same curvature, and the axial feed direction is all $-\mathrm{Z}$, but P3 and P4 are on the convex surface T of the workpiece, while P5 and P6 are on the concave surfaces A. The milling force and milling temperature generated by P6 are greater than those generated by P3, and the milling force and milling temperature generated by P5 are greater than those of P4. Base on the geometric relations, the effective cutting radius at P5 is larger than R1. With the same tool position angle, the concave surface milling area is larger. Because the effective cutting radius $R 1$ is large, the thickness of the milling area increases, resulting in an increase in the milling thermal condition. The milling thermal condition at P6 is greater than that at P5. This is because when these two points are both on the concave surface and the axial feed direction is $-\mathrm{Z}$, with an increase in the curvature, the incision angle is increased, so the actual cutter contact area is enlarged, leading to increases in the milling force and milling temperature. It is indicated that when the curvature is the same, the milling force and milling temperature generated in the concave surface are greater than those in the convex surface. In the concave surface, the milling force and milling temperature increase with an increase of curvature. The results are the opposite of those in the convex surface.

The effects of the four milling parameters (spindle speed, feed per tooth, interval and cutting depth) on the milling forces and milling temperatures are shown in Figs. 16 to 19. 

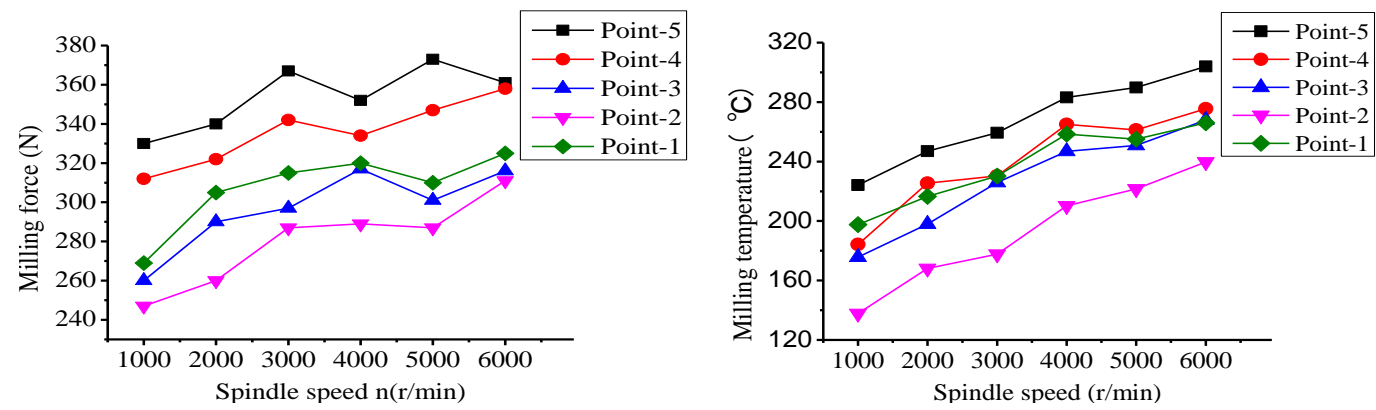

Figure 16: Milling force (left) and temperature (right) changing with spindle speed.
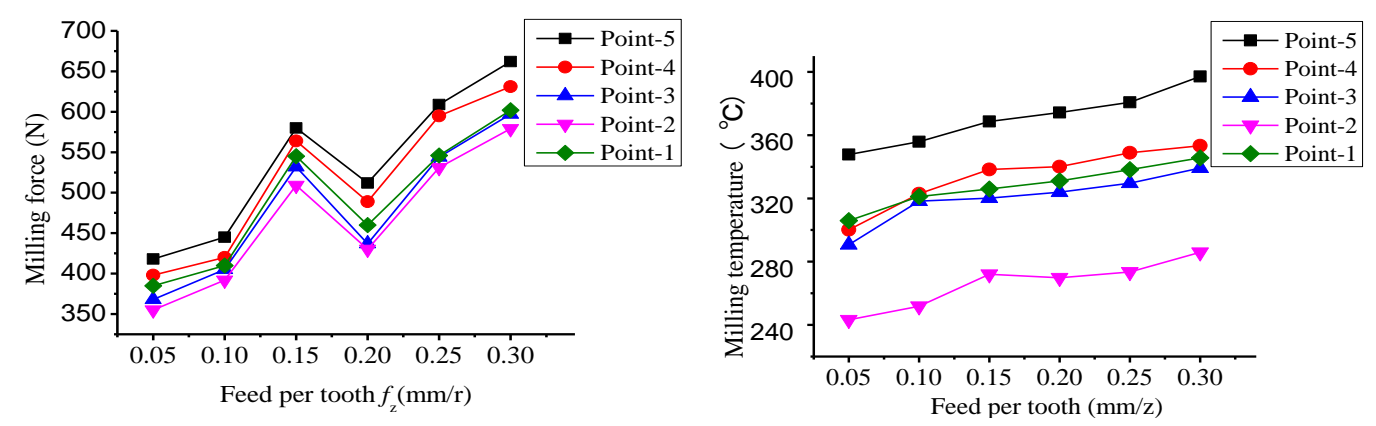

Figure 17: Milling force (left) and temperature (right) changing with feed per tooth.
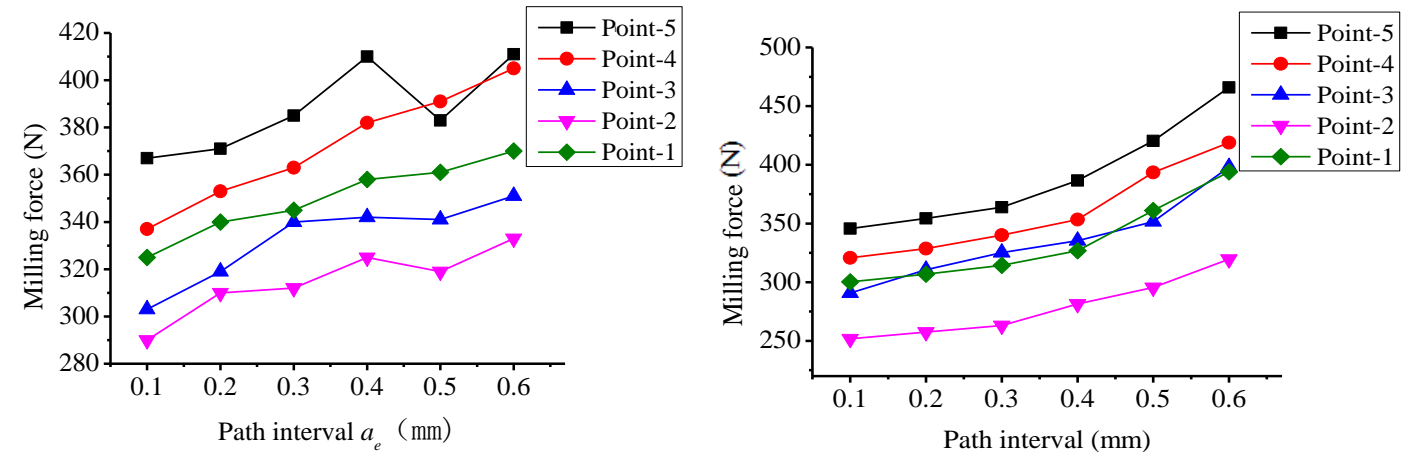

Figure 18: Milling force (left) and temperature (right) changing with path interval.
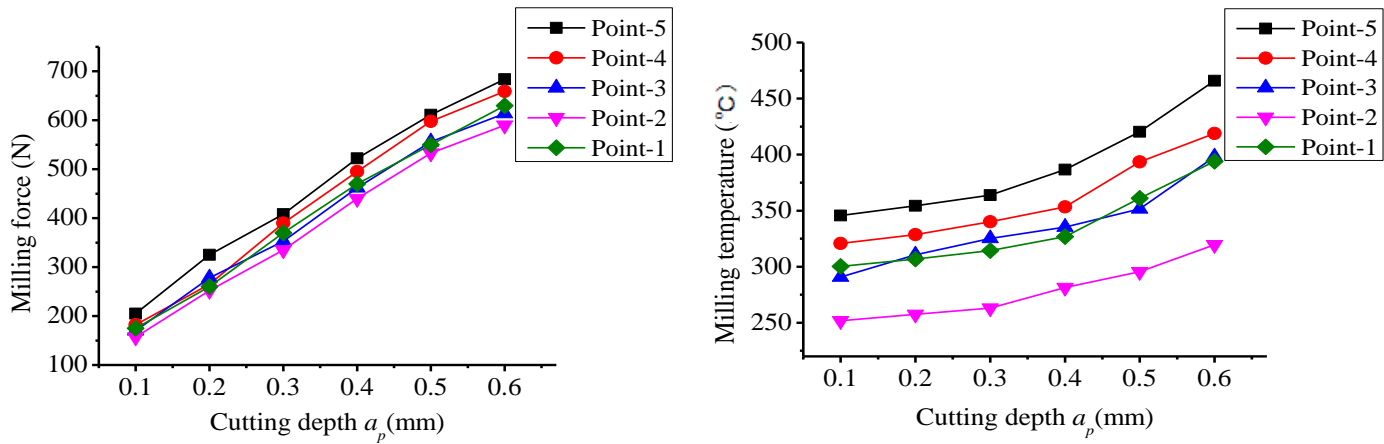

Figure 19: Milling force (left) and temperature (right) changing with cutting depth.

With an increase in the spindle speed, the milling force and milling temperature increase accordingly. But the milling force changes slowly while the milling temperature changes significantly. With an increase in the feed per tooth, the milling force at each feature point has greater fluctuations while the milling force changes slightly and is generally in an upward trend. With an increase in the feed per tooth, generally the milling force increases, but when the feed per tooth is $0.2 \mathrm{~mm} / \mathrm{z}$, it experiences a negative growth and decreases significantly. With a further increase in the feed per tooth, the milling force continues to increase. With an 
increase in the path interval, there are greater fluctuations in the milling force, while the milling temperature rises slowly. When the radial cutting depth is $0.2 \mathrm{~mm}$, the milling force and milling temperature at each feature point are quite concentrated. An increase in the cutting depth will increase the volume of the undeformed chips and leads to a further increase in the cutting force and temperature.

In the parameter range studied in this paper, the concentration of the milling force and milling temperature in different positions of the sine surface indicates that the milling force and milling temperature do not fluctuate much along the tool path, which helps maintain the precision in the machining process. The experiment and simulation analysis indicates that for hardened steel with such surfaces, the milling process is the most smooth and stable when the spindle speed is $4000 \mathrm{r} / \mathrm{min}$ or $6000 \mathrm{r} / \mathrm{min}$, the feed per tooth is $0.1 \mathrm{~mm} / \mathrm{z}$, the radial cutting depth is $0.2 \mathrm{~mm}$ and the cutting depth is $0.1 \mathrm{~mm}$.

\section{CONCLUSION}

A finite element model is proposed to analyse the milling of the assembled transition region in ball-end milling of assembled hardened steel mould. The analysis results show that, the milling force and milling temperature in the assembled transition region change in a stepwise manner. With an increase in the material hardness, the milling force and milling temperature generated in the stable milling region also increase.

The distribution patterns of the stress field and temperature field are analysed under the single-hardness condition. The results show that with an increase in the workpiece hardness, 1) the stress field sensitivity coefficient will be greater, 2) the external load will have wider impact on the workpiece, 3 ) the temperature field sensitivity coefficient will be smaller, and 4) the milling temperature caused by the milling process will be more concentrated and thus bring about a more severe impact.

By adopting the external interface in the DEFORM-3D and the tool positions are resolved by the Matlab software the milling process of hardened steel with sine surface is simulated. By selecting seven feature points on the sine surface, the variation trends of the milling stress field, strain field and temperature field are obtained.

The experiment and simulation indicate that in ball-end milling of hardened steel with curved surfaces, the spindle speed should be $4000 \mathrm{r} / \mathrm{min}$ or $6000 \mathrm{r} / \mathrm{min}$, the feed per tooth should be $0.1 \mathrm{~mm} / \mathrm{z}$, the radial cutting depth should be $0.2 \mathrm{~mm}$ and the cutting depth should be $0.1 \mathrm{~mm}$.

\section{REFERENCES}

[1] Liu, X. L.; Ma, J.; Yue, C. X.; Liu, F.; Zhong, Z. N. (2015). Limit cutting depth prediction for automobile dies finishing machining of convex surface, Journal of Mechanical Engineering, Vol. 51, No. 2, 117-126

[2] Sun, Y. Z.; Liu, H. T.; Lu, Z. S. (2011). Finite element simulation and experimental research of residual stresses in the cutting based on the coupled thermo-mechanical model, Journal of Mechanical Engineering, Vol. 47, No. 1, 187-193

[3] Seshadri, R.; Naveen, I.; Srinivasan, S.; Viswasubrahmanyam, M.; Vijaysekar, K. S.; Kumar, M. P. (2013). Finite element simulation of the orthogonal machining process with Al 2024 T351 aerospace alloy, Procedia Engineering, Vol. 64, 1454-1463, doi:10.1016/j.proeng.2013.09.227

[4] Leopold, J.; Wohlgemuth, R. (2010). Modeling and simulation of burr formation: state-of-the-art and future trends, Proceedings of the CIRP International Conference on Burrs - Analysis, Control and Removal, 79-86, doi:10.1007/978-3-642-00568-8 9

[5] Zanger, F.; Schulze, V. (2013). Investigations on mechanisms of tool wear in machining of Ti6Al-4V using FEM simulation, Procedia CIRP - $14^{\text {th }}$ CIRP Conference on Modeling of Machining Operations, Vol. 8, 158-163, doi:10.1016/j.procir.2013.06.082 
[6] Zhang, W.; Liu, H. L.; Wu, T.; Cui, X. Y.; He, F. S. (2016). Thermal characteristics analysis of hardened steel die transition region in machining process, Materials Science Forum, Vol. 836837, 394-401, doi:10.4028/www.scientific.net/MSF.836-837.394

[7] Chen, M.; Yuan, R. W.; Fan, X. Y.; Yan, J. Q. (2002). Application of three dimensional finite element analysis in cutting temperature for high speed milling, Chinese Journal of Mechanical Engineering, Vol. 38, No. 7, 76-78, doi:10.3321/j.issn:0577-6686.2002.07.017

[8] Bin, L. I.; Deng, J. X.; Duan, Z. X.; Wu, Z. (2010). Simulation and experiment on cutting temperature field considering property of materials and friction, Journal of Mechanical Engineering, Vol. 46, No. 21, 106-112

[9] Cheng, L.; Zhang, C. G.; Xie, F. (2004). On the numerical simulation of the temperature field in metal cutting, Journal of Hefei University of Technology (Natural Science), Vol. 27, No. 9, 1047 1050

[10] Wang, Y. Y.; Ji, S. M.; Wang, H. Q.; Wen, D. H. (2012). Investigation on vibration of ball end milling harden steel assembled with different hardness, China Mechanical Engineering, Vol. 23, No. 6, 636-641, doi:10.3969/j.issn.1004-132X.2012.06.002

[11] Du, C. Q.; Chen, J. B. (2015). Simulation of hard-state finish cutting process based on advantedge, Tool Engineering, Vol. 49, No. 4, 27-31, doi:10.16567/j.cnki.10007008.2015.04.010

[12] Li, G.; Kong, F. Z.; Wang, H. Q.; Zhou, H. D.; Wang, Y. Y. (2014). Finite element analysis of milling force on hardened steels assembled with different hardness, Machine Design \& Research, Vol. 30, No. 5, 130-135, doi:10.13952/j.cnki.jofmdr.2014.0157

[13] Wen, D. H.; Wang, Y. Y.; Ji, S. M. (2011). Numerical simulation on ball end milling harden steel assembled with different hardness, Journal of Harbin University of Science \& Technology, Vol. 16, No. 5, 16-20, doi:10.15938/j.jhust.2011.05.010

[14] Yan, S.; Wang, M. J.; Hu, X. K.; Lu, Y.; Ren, J. L. (2014). The vericut research of titanium alloy based on Deform-3D, Modular Machine Tool \& Automatic Manufacturing Technique, Vol. 10, No. 10, 135-141, doi:10.13462/j.cnki.mmtamt.2014.10.037

[15] Huang, J. L.; Yue, Z. (2011). Simulation study on temperature of dry hard turning of 30CrNiMo8 based on Deform 3D, Machinery, Vol. 49, No. 9, 56-60

[16] Cheng, F. J.; Chen, G. D.; Wang, T. (2012). The simulation analysis for the milling process of ball end mill using the Deform 3D, Mechanical Science and Technology for Aerospace Engineering, Vol. 31, No. 3, 412-416, doi:10.13433/j.cnki.1003-8728.2012.03.011

[17] Li, Y.; Li, Y.; Yang, M.; Yuan, Q.; Cui, F. (2015). Analyzing the thermal mechanical coupling of $40 \mathrm{Cr}$ cold roll-beating forming process based on the Johnson-Cook dynamic constitutive equation, International Journal of Heat \& Technology, Vol. 33, No. 3, 51-58

[18] Rafiee, S. E.; Sadeghiazad, M. M. (2015). 3D numerical analysis on the effect of rounding off edge radius on thermal separation inside a vortex tube, International Journal of Heat \& Technology, Vol. 33, No. 1, 83-90

[19] Li, G. H.; Qi, H. J.; Cai, Y. J. (2015). Study on material dynamic plastic constitutive relationship considering hardness, Journal of Plasticity Engineering, Vol. 22, No. 1, 72-75, doi:10.3969/j.issn.1007-2012.2015.01.014 